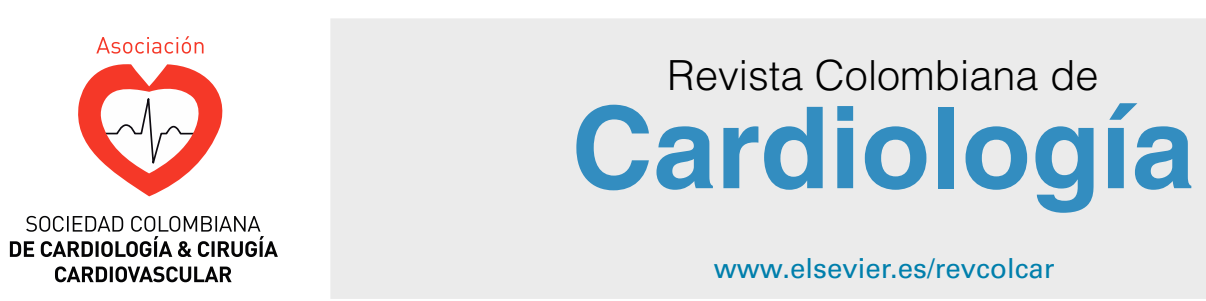

\title{
In memoriam: Dr. Julio Ernesto Coronel Becerra. Homenaje a un colega y amigo
}

\section{In memoriam: Dr. Julio Ernesto Coronel Becerra. Tribute to a colleague and friend}

\author{
José Eustorgio Colmenares
}

Recibido el 22 de febrero de 2019; aceptado el 26 de febrero de 2019

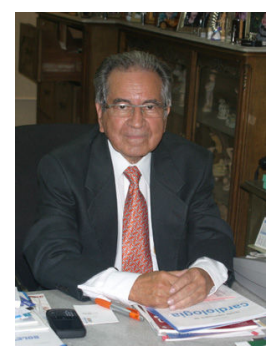

Julio Ernesto Coronel Becerra murió en Cúcuta el 3 de diciembre del pasado año 2018. Tuvo la fortuna, si es que morirse es una fortuna, aunque algunas veces por cruel que parezca sí lo es, de entregar su alma al creador el "Día del Médico', profesión que ejerció durante casi seis décadas y a pocas semanas de cumplir 90 años de existencia.

Había nacido el 20 de enero de 1929, en la célebre población de La Villa del Rosario, conocida por ser la cuna del prócer colombiano Francisco de Paula Santander y cuyo Templo Histórico fue la sede del Congreso de Cúcuta en 1821 en el cual se dio el nacimiento de la Gran Colombia.

Médico de la Universidad Nacional de la promoción 1954, realizó sus estudios de especialización en el famoso Instituto de Cardiología Ignacio Chávez de la ciudad de México en los años 1957 a 1959, luego de lo cual regresó a su región de

Correo electrónico: jesucosa@gmail.com origen a aplicar los conocimientos adquiridos para beneficio de sus futuros pacientes.

En 1958 contrajo matrimonio con Marina Jordán Peñaranda en Cúcuta, del cual son sus descendientes, su hija Isabel Cristina Coronel Jordán, casada con Eduardo Durán Gómez, santandereano, hoy Presidente de la Sociedad Colombiana de Historia, y sus dos nietos, Sofía Cristina y Julio Eduardo Durán Coronel.

A su regreso se vinculó al Hospital San Juan de Dios de Cúcuta e inició su práctica privada, en la cual, gracias a su sabiduría y a su don de gentes, fue haciéndose conocer en el medio.

Por esa época, Cúcuta tenía fama de ser muy buena plaza para el ejercicio privado de la Medicina en sus diferentes ramas ya que sus profesionales y clínicas tenían gran aceptación en las vecinas ciudades venezolanas, además de las ventajas de la fortaleza de su moneda (Bolívar), haciendo que de muchas partes de Venezuela acudieran los pacientes a consultar a los médicos cucuteños, que en esas épocas, entre 1965 y 1990, recibían gran cantidad de enfermos no solo provenientes del vecino país, sino los propios de nuestra ciudad y sus municipios aledaños.

Como anécdota, cuando quien escribe esta nota estaba estudiando bachillerato y vivía a dos cuadras del consultorio del doctor Coronel, me llamaba la atención la cantidad de gente que hacía filas afuera de su consultorio para alcanzar a conseguir ser atendidos por él en el curso del día. 
Luego, durante mi ejercicio de la medicina lo pude conocer y alternar con él, y así apreciar sus cualidades, tanto como persona, que como profesional. Siempre fue Julio Coronel un ser de extrema sencillez, muy afable y cordial con quienes se relacionaba, al igual que con sus pacientes, independientemente de sus condiciones. Gran trabajador durante toda su vida, pues hasta sus últimos días, pese a su edad, madrugaba a hacer sus rondas en las clínicas y permanecía en su consultorio así ya no tuviera la gran afluencia de pacientes que atendió en sus primeras décadas de ejercicio profesional.

En el ejercicio médico fue un profesional exitoso, que se capacitaba permanentemente con el fin de estar actualizado con los avances de la Medicina Interna y la Cardiología, las cuales, como se mencionó, ejerció desde 1960 hasta pocos días antes de su fallecimiento. Socio de las clínicas Santa Ana y Norte, de las cuales fue Director Científico, en la primera, y varias veces miembro de las Juntas Directivas de ambas; trabajó en los servicios de Cardiología del antiguo Hospital San Juan de Dios y posteriormente del Erasmo Meoz; presidió el único congreso Nacional de Cardiología realizado en Cúcuta en 1987; fue Magistrado del Tribunal de Ética Médica del Departamento, y presidió la Sociedad Colombiana de Medicina Interna en su Capítulo local, así como la Sociedad de Cardiología de los Santanderes, e igualmente fue Vocal de la Sociedad Colombiana de Cardiología.

Se desempeñó como Profesor en la Universidad Libre de Cúcuta y fue autor de varios artículos de la especialidad para revistas y textos nacionales, al igual que expositor en múltiples oportunidades en congresos y simposios de cardiología locales y nacionales.

Muy apreciado en el gremio y entre quienes lo conocieron en todo el país; se dedicó siempre a estar al día en los adelantos científicos y poder entregar a sus pacientes lo mejor de su bagaje académico. La noticia de su fallecimiento causó hondo pesar, no sólo entre sus colegas de todo el país, sino también en la sociedad cucuteña, donde era célebre y respetado.

Paz en su tumba. 